\title{
Practice and Research on the Self-directed Learning of Nursing Clinical Teaching
}

\author{
Zhijuan Liu ${ }^{1}$, Haiyan Deng ${ }^{2}$, Jing Huang ${ }^{3}$ and Xiaoran Qiu $^{2 *}$ \\ ${ }^{1}$ The School of Public Health, XiangNanUniversity, Chenzhou, 423000,Hunan,China \\ ${ }^{2}$ The School of Nursing, XiangNanUniversity ,Chenzhou, 423000, Hunan,China ${ }^{3}$ Affiliated Hospital, \\ XiangNanUniversity,Chenzhou, 423000, Hunan,China \\ hulixue22@163.com \\ ${ }^{*}$ Corresponding Author
}

KeyWords: Self-learning; Nursing; Clinical Teaching

\begin{abstract}
This paper elaborates the connotation as well as characteristics of self-directed learning, which applies it to nursing clinical teaching. The experiment shows that this learning method excels over others in terms of improving learning interest, initiative, expression skill, team-work spirit, communication ability, critical thinking ability, ability to solve problems, professional quality and patient satisfaction. What's more, the average grade, qualification ratio and outstanding students ratios are superior to the control group. At last, this paper comes up with implementation countermeasures for applying self-directed learning to nursing clinical teaching.
\end{abstract}

\section{Introduction}

Nursing clinical teaching is a bridge linking theory to practice, which can improve students ' skills and overall quality, shorten the distance between teaching and clinic, playing an important role in nursing education. However, the current condition is that nursing teaching focuses on knowledge indoctrination and ignores the cultivation of critical thinking ability. While nurses students come into the clinic, they excessively rely on medical order, and never question about the rationality without independent thinking, showing the lack of ability to comprehensively apply knowledge. Traditional nursing education model with teacher and book as the center is not conducive to the cultivation of students' comprehensive ability and their development. Therefore, discussing a new nursing teaching model is imperative.

\section{The Connotation of Self-Directed Learning}

Self-directed learning refers to the process that individual students take the initiative to come up with learning targets and tasks so as to intentionally plan, adjust, supervise and evaluate the learning activity based on the continuous psychic and physical development and change, and with the assistance of their companion and teachers. At the same time, it is also a process for learners to acquire certain knowledge, skills to develop and form a health personality, and improve self-learning ability with effective policies and methods.

Self-directed learning is not only a process for leaners to take the initiative to learn but also a process to acquire knowledge, skill and develop personalities adapted to learning readiness as well as preparation. In addition, it requires clear learning targets and learners can take teachers, learning companions as learning resources while take all guidance and communication as effective methods, and meanwhile make plans, monitoring, adjustment and evaluation on themselves. All these prove that self-directed learning needs educators to change their traditional teaching philosophy, which also emphasizes on helping learners to complete learning tasks and realize goals. Besides, leaners should gradually change dependent learning model to self-directed learning model under the guidance of educators. 


\section{Related Theoretical Basis}

(1) Humanistic Learning Theory

Humanistic learning theory holds the idea that the nature of human beings is positive and self-fulfilling while learning is the process for people to realize their potentials. Therefore, we should emphasize that the learning process should be the process for learners to self-guide and develop themselves, which should take leaners as the center and stimulate their enthusiasm so as to help them have self-guided learning and free learning learning in a positive, harmonious, and safe environment. In the process of learning, teachers should let them feel that he or she might be a sincere, realizable and emotional tutor.

(2) Adolescent Development Psychology

Adolescents are almost mature both from psychology and personality. They develop not only from abstract logic but also are longing for knowledge and future in daily life. What's more, they have strong emotions and are able to carry out creative learning and quickly develop self-consciousness to from initial world outlook and values.

(3) Social Psychology Group Theory

In school, class group is the basic element, which will cause a tremendous effect on individuals, the class and the school at large. At the same time, whether the self-directed learning can be successfully implemented in school teaching and achieve goals is also related to the class group.

\section{Analysis on the Teaching Effect of Self-Directed Learning}

This paper secrets 58 people of nursing class 1 of 2012 as the experiment group and 54 people of nursing class 2 as the comparison group. They are students enrolled based on national college entrance and are randomly divided into different class, so there is no statical difference between these two group in terms of learning record, sex, age. The experiment group adopts self-directed learning, which encourage students to take advantage of the learning resources around them to carry out self-directed earning based on learning schedule. What's more, each Friday, there will be group discussion with nursing students as the center to focus on relative knowledge and nursing measures of common disease in terms of internal medicine as well as surgery. Furthermore, teachers plays a role in leading the direction of the discussion and creating the atmosphere. After the discussion, the tutor will carry out a brief summary and ask students to reflect on themselves. The comparison group adopts traditional teaching method. By the way, the tutors, total class hours, weekly hours as well as test contents are same in order to ensure that there is no statical difference in terms of general information. So, these two groups are comparable.

After the teaching, there will be questionnaires on these two groups, which are collected by secret ballot. 112 questionnaires sent are all effective. The main investigation terms include learning interest, initiative, self-learning ability, expression skill, team-work spirit, communication ability, critical thinking ability, ability to solve problems, professional quality and patient satisfaction etc, and the result is shown in Table 1.

Every record of experiment group is obviously higher than the comparison and the total record is superior. 
Table 1 Student questionnaire result

\begin{tabular}{cccc}
\hline Items & Experiment group & Comparison group & $\chi^{2}$ P value \\
\hline Learning Interest & 95 & 70 & $<0.01$ \\
Learning Initiative & 93 & 69 & $<0.01$ \\
Self learning ability & 87 & 66 & $<0.05$ \\
Expression skill & 93 & 63 & $<0.01$ \\
Team work spirit & 88 & 87 & $<0.01$ \\
Communication ability & 96 & 72 & $<0.01$ \\
Critical thinking ability & 93 & 76 & $<0.01$ \\
Ability to solve problems & 98 & 71 & $<0.01$ \\
Professional quality & 89 & 72 & $<0.01$ \\
Patient satisfaction & 96 & 65 & $<0.05$ \\
GPA & 92.8 & 71.1 & $<0.01$ \\
\hline
\end{tabular}

At the same time, there will be theoretical and operation closed-book exam on experiment group and comparison group. The written test takes basic theory and application as the testing sites and the topics include subjective and objective ones based on hundred-mark system. All the collected materials will be organized and set into a data base while the statistic software SPSS 19.0 will be adopted to carry out descriptive statistics and test as well as $\chi^{2}$ test. The academic record analysis of two methods is shown in Table 2.

Table 2 Analysis on the academic record of two teaching methods

\begin{tabular}{ccccc}
\hline \multicolumn{2}{c}{ Items } & Experiment group & Comparison group & $\chi^{2}$ P value \\
\hline \multirow{3}{*}{ Theoretical test } & Average score & 82.6 & 68.3 & $<0.01$ \\
& Outstanding rate & 39.85 & 16.75 & \\
& Pass rate & 95.12 & 92.31 & \\
& Average score & 86.7 & 67.5 & $<0.05$ \\
Operation test & Outstanding rate & 41.13 & 17.66 & \\
& Pass rate & 97 & 93.31 & \\
\hline
\end{tabular}

The score of these two group is in normal distribution and the average score, outstanding rate as well as pass rate of the experiment score are higher than the comparison group.

\section{Countermeasures for Applying Self-Directed Learning in Nursing Clinical Teaching}

\section{Update ideas.}

(1) Set up the concept of people-orientation

Always keep in mind the concept of people-orientation, comprehensively develop all students.

(2) Set up new students sight, pay attention to individual orientation

The development of students should not only pay attention to general, comprehensive and proactive prestige but also the difference and continuity.

(3)Set up new talent view, pay attention to multi talent training mode 
While emphasizing that students should master the basic knowledge and skills, their ability to learn and communicate with other people, their innovative and practical skills should also be paid attention to so as to make them satisfy the requirements of economy and society in the new era.

(4)Positively realize the change of learning method

Advocate independent, inquisitive and communicative learning method.

(5)Set up new teaching concept, focus on the communication and interaction between teachers and students

The teaching process refers to the interaction communication and mutual development between teachers and students which is able to build a humanistic, harmonious, and equal reaction between them. Teachers are helpers and tutors for students who organize and implement learning activities, always pay attention to the learning process and give guidance as well as feedback. With the continuous assistance of teachers, students can communicative with them based on different approaches, report their results with feedback and raise questions.

Define Learning Subjectives.Teachers should help students to make their determination to carry out self-directed learning and come up with overall, hierarchical, dynamic and inspirational goals based on facts so as to improve learning efficiency.

Promote the Deep inTegration between Information Technology and Educational Teaching. Set up efforts on information technology training, improve the information quality of teachers and students. Positively develop, enrich and perfect teaching resources to digitize them and put them on internet to fully apply information technology and internet space into teaching.

Cultivate Good Learning Atmosphere. The teaching environment should be bright, comfortable, simple and liberal while the teaching equipments should be conducive to the communication between teachers and students. What's more, students should be mutually friendly, respectful, supportive, responsible and trust each other so that they can have a positive learning environment with both cooperation and competition.

\section{Acknowledgements}

Supported by Twelfth Five-Year Plan topic of Hunan Education and Science (Empirical research on the self-directed learning of nursing clinical teaching XJK012CGD032).

\section{References}

[1] Q.Y. He, J.S. He: Journal of Hebei Normal University (Education science), Vol. 11 (2009) No.2,p.33.

[2] T.X. Zha: Journal of Clinical and Experimental Medicine, Vol.11(2007) No. 11,p.181.

[3] X.M. Li, J. Li: Journal of Nursing Science, Vol. 19 (2004) No. 9, p.19.

[4] Q. L. Zheng:Hygiene education, (2009) No.2.

[5] W.G. Pang: Journal of Developments in Psychology, (2000) No. 4,p.12.

[6] M. Gibbons: Self-directed learning handbook:challenging adolescent students excel (San Francisco:Jossey-Bass,2002).

[7] M.See Knowles: Self-directed learning:A guide for learners and teachers(The Adult Education Company,Toronto 1975),p.9.

[8] B.H. Chen, A.L. Jiang and S.Z.: China Higher Medical Education, (1998)No.1,p7.

[9] F.Q. Huang: Modern Course and instructional theory ( People's education process, China,2006).

[10]H.Y. Deng, X.Y. Jia and P. Li etc: Clinical research and practice, (2016)No.9,p.118. 